Diesen Dorn sticht man so nahe, wie möglich, an der Wurzel der Schwanzfedern zwischen diese ein. Und man trift mit ihm vorweg den richtigen Punkt hierzu jedenfalls besser, als mit dem beiläufigen Anoder Auflegen des Maassstabes̀ allein : zumal, wenn man zuvor mit seiner Spitze gleichsam "sondirt". Denn, zu weit oberwärts eingesetzt, wo er noch den Bürzel trifft, dringt er natürlich überhaupt gar nicht ein, macht also zum Voraus jeden Fehler in Betreff des Zuviel unmöglich. Anderenfalls aber lässt er, wenn man ihn mit dem Daumen der anderen Hand zurückdrückt, sich leicht ohne merkliche Störung der Federn sehr genau bis an den Bürzel nach oben schieben. Dann ist jede Möglichkeit

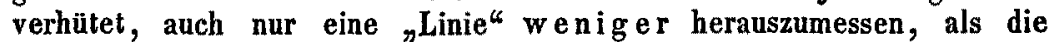
wirkliche Länge der Federn oder jeder beliebigen einzelnen von ihnen beträgt.

So äusserst nahe übrigens dieses Auskunftsmittel auch liegt, so kam es doch erst kürzlich noch einem sehr geübten und sehr vorsichtig mit Naturalien umgehenden Praktiker so neu vor, dass ich dasselbe hier zu weiterer Anwendung habe empfehlen wollen.

Berlin, im April 1853.

Gloger.

\title{
Nachrichten.
}

\section{Zur Erinnerung.}

Die diessmalige Jahresversammlung der deutschen Ornithologen-Gesellschaft wird, dem auf der letztjährigen Versammlung in Altenburg gefassten Beschlusse zufolge, im Juli d. J. z n Halberstadt abgehalten. Die Sitzungen sind auf

\section{Dinstag den 12. Juli}

und die nächstfolgenden beiden Tage festgesetzt. Am vorhergehenden Montage, den 11. Juli Abends, wird voraussichtlich, dem bisherigen Gebrauche gemäss, wieder eine einleitende Vorversammlung anberaumt werden.

Die erforderlichen Räumlichkeiten zu den Zusammenkünften sind von dem Local-Geschäftsführer, Herrn Oberamtmann $\mathrm{H}$ e in e, im Hôt $\mathrm{el}$ de Prusse (bei Spendelin) am Domplatze bestellt. Zugleich ist dafür gesorgt, dass auch die zur Versammlung kommenden Herren Theilnehmer nach Belieben ebendaselbst Unterkommen finden können.

Jeder Ornitholog und Freund der Ornithologie hat zu den Sitzungen freien Zutritt; und die allseitige Förderung dieses Zweiges der Naturkunde macht einen recht zahlreichen Besuch derselben sehr erwünscht. Desshalb hat die entfernter wohnenden Ornithologen auf die bevorstehende Versammlung rechtzeitig aufmerksam zu machen sich erlauben wollen

Berlin, im April 1853.

der Herausgeber. 